\title{
Anomalous Specific Heat of Permalloys
}

\author{
By Sadami Tomita*
}

\begin{abstract}
To interpret the change of magnetic property caused by relatively low temperature heat-treatment, the $\mathrm{Cp}$ - $\mathrm{T}$ curves of molybdenum-permalloy and 50-permalloy were determined by the improved Sykes-Jone's methods, Cp-T anomalous curves occur between $400^{\circ}$ to $550^{\circ} \mathrm{C}$, relating to atom ordering and magnetic tpansformation. When the specimen was quenched from $650^{\circ} \mathrm{C}$, the specific heat decreases at temperatures above $420^{\circ} \mathrm{C}$. Annealing at $440^{\circ} \mathrm{C}$ did not cause the appearance of decreasing specific heat. From the experimental results, it was concluded that the atom order in the above permalloy materials does not occur in the form of long range order but short range order, and the change of magnetic property is due to the origination of the short range ordered phase by low temperature heat treatment.
\end{abstract}

(Received July 27, 1962)

\section{Introduction}

Binary permalloys and polynary permalloys are technically important as high permeability materials. $\mathrm{Ni}-\mathrm{Fe}^{(1)}, \mathrm{Ni}-\mathrm{Fe}-\mathrm{Mo}^{(2)}, \mathrm{Ni}-\mathrm{Fe}-\mathrm{Cu}-\mathrm{Cr}$ and other alloys undergo a remarkable change of $H_{c}$ (coercive force), $\mu_{0}$ (initial permeability), $\mu_{\mathrm{m}}$ (maximum pevmeability) when heat-treated between $300^{\circ} \mathrm{C}$ to $600^{\circ} \mathrm{C}$. The interpretation of these effects which are caused by relatively low temperature heat-treatment of $\mathrm{Fe}-\mathrm{Ni}$ alloys was begun by verifying the $\mathrm{Ni}_{3} \mathrm{Fe}^{(3)}$ superlattice formation.

Next, the change of magnetoanisotropy and magnetostriction of the crystal was considered in relation to the ordering of atoms of the alloy, to explain these effects ${ }^{(4)}$. According to the investigation for the change of the electrical resistivity, however, the sign of the change is opposite to that which is supported by the idea of superlattice transformation in the case of polynary permalloy(5)(6). Moreover, in the case of general kinds of permalloy, we found that the magnetic property, such as $\mu_{0}$ and $\mu_{\mathrm{m}}$, affected by the relatively low temperature heat-treatment could not be satisfactorily explained by the change of magnetoanisotropy and magnetostriction of the material.

In this investigation, we measured the specific heat of two permalloys, molybdenum permalloy (4 Mo-79 $\mathrm{Ni}-\mathrm{Fe})$ and 50 permalloy, $(50 \mathrm{Ni}-\mathrm{Fe})$, and ascertained the existence of the superlattice-formation, and tried to explain the effects of relativey low temperature heattreatment of these permalloys.

\section{Experimental Method}

\section{Preparation of specimens}

The specimen used for the measurement of specific heat is the same as that for the magnetic property. We prepared specimens consisting of the two pieces, that is, one piece was formed into a cylindrical tube so

* Hitachi Research Laboratory, Hitachi.

(1) G. W. Elmen: J. Franklin Inst., 207 (1929), 583.

(2) G. W. Elmen: E. E., 54 (1935), 1292.

(3) O. Dahl : Z. Metallkunde., 28 (1936), 133.

(4) R. M. Bozorth and J. G. Walker : Phys. Rev., 89 (1953), 624.

(5) F. Assmus and F. Pfeifer : Entwicklungsberichte, 16 (1953), 337.

(6) S. Tomita : J. Phys. Soc. Japan, 16 (1961), 393.

Trans. J IM as to wind wire and the other is formed into a lid so as to prevent the radiation loss of heat. We used two kinds of permalloy: (1) polynary permalloy (4 Mo$79 \mathrm{Ni}-\mathrm{Fe}$ ) and (2) binary permalloy (50 Ni-Fe). To make the alloys, we used high purity electrolytic nickel, electrolytic iron and others with high purity elements. They were carefully melted in vacuum. Then the specimens were made by forging the ingots. The mechanical stress, during working, was released by annealing at high temperature. To protect them from oxidation and reduce non-metallic impurity, the specimens were annealed in an atmosphere of pure hydrogen gas. The specimens were furnace-cooled after high temperature annealing at $1150^{\circ} \mathrm{C}$, and then rapidly reheated to $650^{\circ} \mathrm{C}$ for 1 hour, in a non-inductive furnace for the purpose of normalization-heat-treatment, and were rapidly cooled to temperatures, rangeing from $600^{\circ} \mathrm{C}$ to $300^{\circ} \mathrm{C}$ and held for 20 hours at the constant temperature.

\section{Measurement of specific heat}

For the measurement of specific heat at high temperature, the improved apparatus of Sykes-Jone's which was reported by Takagi and Nagasaki ${ }^{(7)}$ was installed. The reproducibility of experimental results was sufficient using this apparatus. The heating rate of the specimen was about $1^{\circ} \mathrm{C} / \mathrm{min}$. The deviation from thermal equilibrium was less than $\pm 0.05^{\circ} \mathrm{C}$. The specific heat vs. temperature curve $\left(\mathrm{C}_{\mathrm{p}}-\mathrm{T}\right.$ curve) was obtained in ranges up to $600^{\circ} \mathrm{C}$ and plotted at temperature intervals of $2^{\circ} \mathrm{C}$.

\section{Measurement of magnetic property}

The magnetic property of the specimen heat-treated at each temperature was examined before the measurement of specific heat. The magnetization curve (B-H curve) of the cylindrical tube was measured by the ballistic-galvanometer method.

\section{Experimental Results}

Specific heat vs temperature curves are plotted in the range from $300^{\circ} \mathrm{C}$ to $600^{\circ} \mathrm{C}$. Fig. 1 shows the $\mathrm{C}_{\mathrm{p}}-\mathrm{T}$ curves of molybdenum permalloy and 50-permalloy by

(7) T. Takagi and S. Nagasaki : Oyo-Buturi, 17 (1948), 104. 
rapid cooling heat-treatment from $650^{\circ} \mathrm{C}$. The $\mathrm{C}_{\mathrm{p}}-\mathrm{T}$ curves in the case of annealing for $20 \mathrm{hrs}$. at $440^{\circ} \mathrm{C}$, $470^{\circ} \mathrm{C}$ and $490^{\circ} \mathrm{C}$ are shown in Fig. 2, Fig. 3 and Fig. 4, respectively. In Fig. 5 and Fig. 6, the B-H curves of molybdenum permalloy and 50-permalloy are shown.

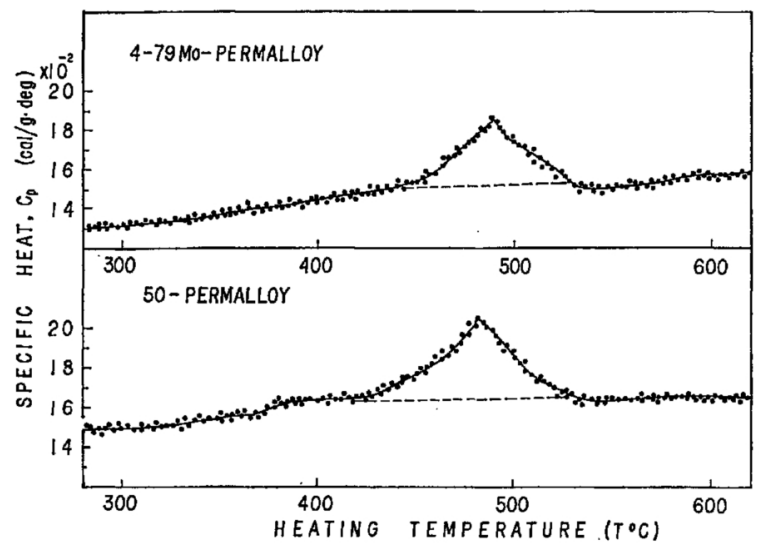

Fig. 1 Specific heat vs temperature curves for specimens annealed at $440^{\circ} \mathrm{C}$.

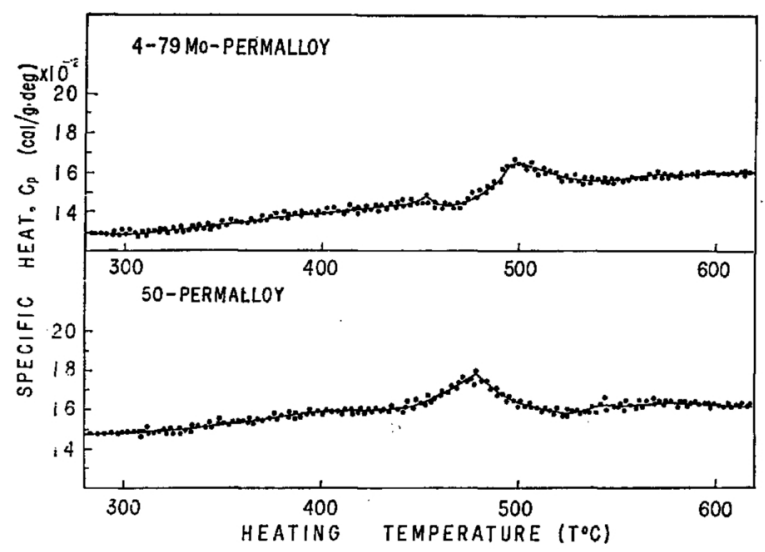

Fig. 2 Specific heat vs temperature curves by the annealing at $470^{\circ} \mathrm{C}$.

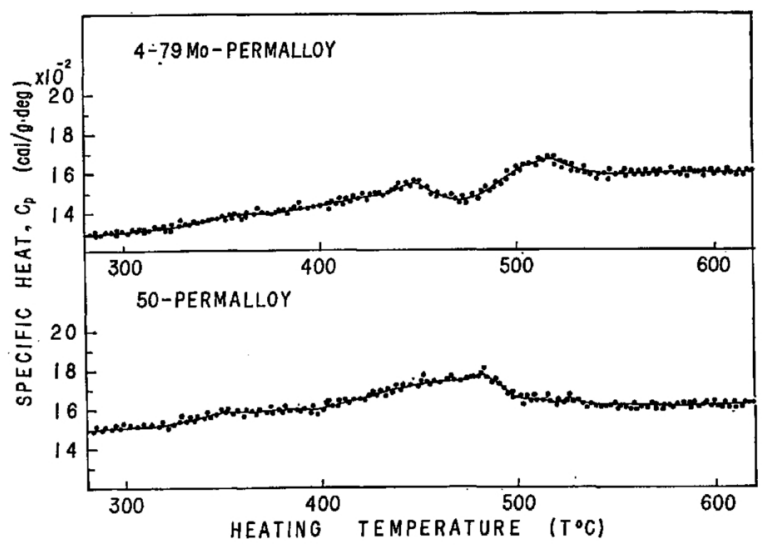

Fig. 3 Specific heat vs temperature curves for specimens annealed at $490^{\circ} \mathrm{C}$.

\section{Theoretical Consideration}

The curves of specific heat vs the temperature of the ferromagnetic material show the abnormality near the Curie point. This abnormality of the curves is due to the magnetic phase change. The Curie points of 4. Mo-79 Ni-Fe and $50 \mathrm{Ni}-\mathrm{Fe}$ alloys are $460^{\circ} \mathrm{C}$ and $480^{\circ} \mathrm{C}$. As is well known, an ordering of atoms occurs in iron-nickel alloy. The critical temperature of superlattice $\mathrm{Ni}_{3} \mathrm{Fe}$ is about $490^{\circ} \mathrm{C}$. Therefore, we cannot observe the heat change by distinguishing the part associated with atom-ordering from the part by the magnetic phase change occurring in the same temperature range. In general, however, the magnetic part of specific heat is considerably small compared with the

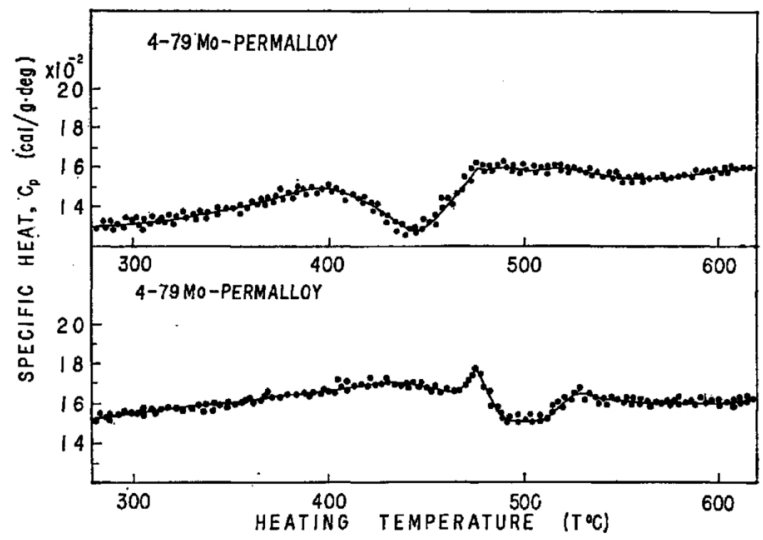

Fig. 4 Specific heat vs temperature curves for specimens rapidly cooled from $650^{\circ} \mathrm{C}$.

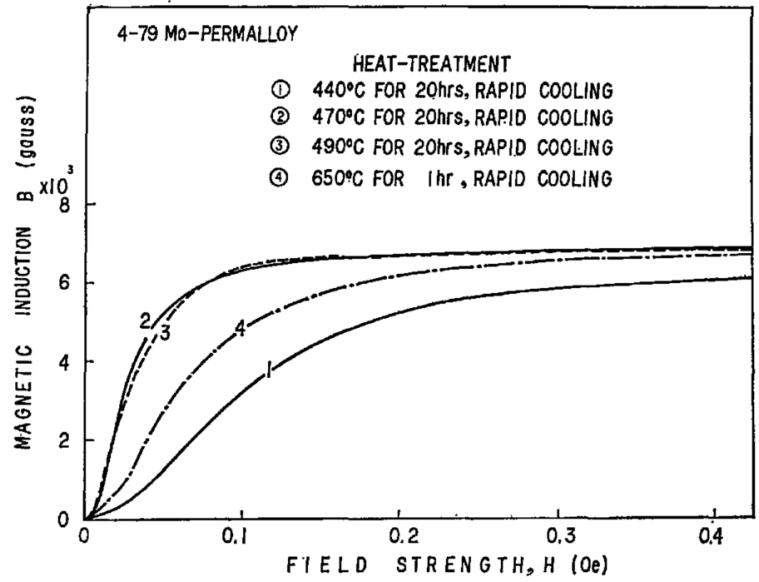

Fig. 5 Magnetization curves of 4-79 molybdenumpermalloy.

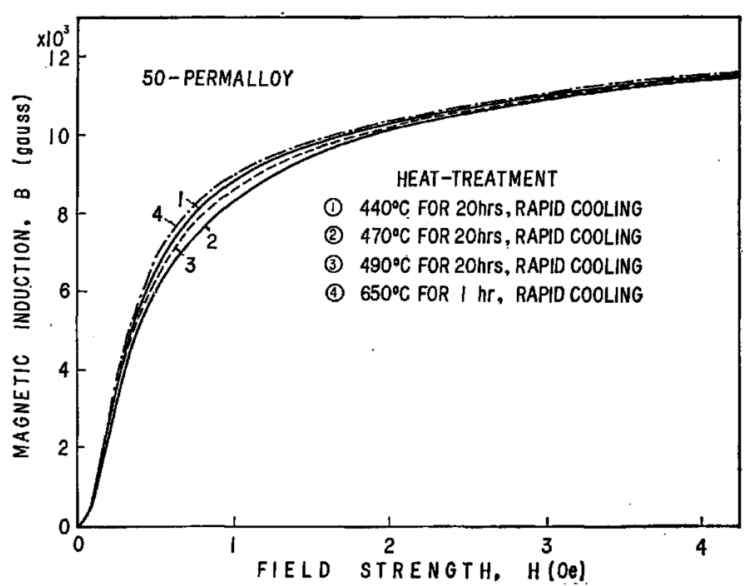

Fig. 6 Magnetization curves of 50-permalloy.

term due to the atom ordering. Therefore, the main abnormality of the $\mathrm{C}_{\mathrm{p}}-\mathrm{T}$ curve, shown in Fig. 1 is induced by the change of atom order, and it is supposed that the magnetic part near the Curie point is masked by th atom ordering part.

In the case of annealing at $440^{\circ} \mathrm{C}$ (Fig. 1), the peak of $\mathrm{C}_{\mathrm{p}}-\mathrm{T}$ curve is shown at $490^{\circ} \mathrm{C}$ for Mo-permalloy and at $480^{\circ} \mathrm{C}$ for 50 -permalloy, respectively. If we draw the base line as shown by the broken line in the 
figure, the excess heat absorption is calculated to be about $1 \mathrm{cal} / \mathrm{gr}$, or $60 \mathrm{cal} / \mathrm{mean} \cdot \mathrm{mol}$, which is very small in comparison with $20 \mathrm{cal} / \mathrm{gr} \cdot \operatorname{deg}^{(8)}$ of perfect ordering $\mathrm{Ni}_{3} \mathrm{Fe}$ alloy.

Annealing at a temperature just below and just at the order-disorder transformation point, $470^{\circ} \mathrm{C}$ and $490^{\circ} \mathrm{C}$, shown in Figs. 2 and 3 , the amount of atom order is small on account of the slow transformation speed.

In the Mo-permalloy, the specific heat begins to decrease from $460^{\circ} \mathrm{C}$ in the course of the heating process, associated with formation of atom ordering, and succesively, the specific heat increases at higher temperature, reaching a maximum at $500^{\circ} \mathrm{C}$ or $510^{\circ} \mathrm{C}$ associated with the disappearing of existing ordering., On the other hand, in the case of 50-permalloy, the temperature at the peak of the $\mathrm{C}_{\mathrm{p}}-\mathrm{T}$ curve is almost independent of the annealing temperature. Namely, the peak of the $\mathrm{C}_{\mathrm{p}}-\mathrm{T}$ curve appears at $480^{\circ} \mathrm{C}$ by annealing at $440^{\circ} \mathrm{C}$ and $480^{\circ} \mathrm{C}$ and $475^{\circ} \mathrm{C}$ by annealing at $490^{\circ} \mathrm{C}$ and $470^{\circ} \mathrm{C}$, respectively. This is explained by considering the fact that the transformation of 50 -permalloy is much faster than of Mo-permalloy.

When the specimens are rapidly cooled from $650^{\circ} \mathrm{C}$, the retardation of atom ordering is observed more obviously than in the previous cases. Namely, the decreasing of the specific heat appears at lower temperature and the amount of decrease becomes larger. In the rapidly cooled 50-permalloy specimen, however, the small peak of the $\mathrm{C}_{\mathrm{p}}-\mathrm{T}$ curve is observed at $475^{\circ} \mathrm{C}$, being slightly low, compared with annealing at $440^{\circ} \mathrm{C}$.

The B-H curves of the specimens are show in Fig. 5 and Fig. 6 ; the $\mathrm{B}-\mathrm{H}$ curves correspond to the $\mathrm{C}_{\mathrm{p}}-\mathrm{T}$ curves, which are obtained by low temperature heat treatment. In Mo-permalloy, the difference of $\mathrm{B}-\mathrm{H}$ curves appears obviously with each heat treatment, but the B-H curves of 50-permalloy with different heat treatments are similar to each other.

A higher permeability of Mo-permalloy is obtained by annealing near the order-disorder point, $490^{\circ} \mathrm{C}$ and $470^{\circ} \mathrm{C}$. Compared the two cases of annealing at $440^{\circ} \mathrm{C}$, being expected sufficient atom ordering, and quenching from $650^{\circ} \mathrm{C}$, being expected retardation of atom ordering. Consideration this evidence, it can be recognized that the high permeability state of Mo-permalloy matches the adequate ordering. In 50-permalloy, however, the high permeability matches the retardation of atom ordering as in the case of quenching from $650^{\circ} \mathrm{C}$.

Now if it is assumed that in the partially ordered state particles very fine ordered phase having the composition $\mathrm{Ni}_{3} \mathrm{Fe}$, precipitates in the matrix by the low temperature heat treatment mentioned above. Then on account of the contraction of volume due to the atom ordering (contraction is about $10^{-4}$ in the fractional change of perfect order $\mathrm{Ni}_{3} \mathrm{Fe}$ ), internal stress originates in materials. By Kersten, the relation between magnetic property and internal stress was considered theoretically. Concerning the domain wall displace-

(8) S. Kaya : J. Fac. Sci. Hokkaido Univ., 2 (1938), 29."

(9) S. Kaya: Rev. Mod. Phys., 25 (1953), 49. ment, he showed that the thickness of the domain boundary (Bloch wall) and the localized extent of internal stress affects the permeability or coercive force, and the origination of such internal stress that the period of stress potential barrier is smaller than the thickness of domain boundary results in a higher permeability state. We can consider that this is the case when annealing Mo-permalloy at $470^{\circ} \mathrm{C}$ or $490^{\circ} \mathrm{C}$. And, also growth of the ordered phase by annealing at $440^{\circ} \mathrm{C}$ results in damage to the high permeability state, because the period of stress fluctuation in the material will exceed the thickness of the domain boundary.

And yet, the low permeability for the specimen rapidly cooled from $650^{\circ} \mathrm{C}$ will be attributable to the supposition that the fluctuation period of internal stress is comparable with thickness of domain boundary.

In 50-permalloy, although the abnormall part of the specific heat curve appears as much as in Mo-permalloy, the change of the $\mathrm{B}-\mathrm{H}$ curves with heat treatment is very small. This phenomenon is explained by considering that the magnetoanisotropy of this alloy is greater than that of Mo-permalloy, and the magnetic property is insensitive to the existence of internal stress, and then, the highest permeability obtained by rapidly cooling from $650^{\circ} \mathrm{C}$, may be due to the small magnetoanistropy constant by this heat treatment.

We can not estimate sizes of such a fine ordered phase directly from the specific heat curve. But, assuming that the number of nuclei for the formation of ordered phase precipitates is almost invariable in the same alloy with the same normalization heat treatment (quenched from $650^{\circ} \mathrm{C}$ ), we can obtain knowledge of the density of an ordered particle from each $\mathrm{C}_{\mathrm{p}}-\mathrm{T}$ curves, as well as information about the fluctuation period of the stress mentioned above and based on the results we explain the $\mathrm{B}-\mathrm{H}$ curves changed by low temperature heat treatment at $440^{\circ} \mathrm{C}, 470^{\circ} \mathrm{C}$ and $490^{\circ} \mathrm{C}$, respectively.

\section{Summary}

The specific heat of two kinds of permalloys: molybdenum-permalloy and 50-permalloy were measured. The abnormality of the specific heat vs temperature curve asscociated with an ordering of atoms was observed. The abnormality of the $\mathrm{C}_{\mathrm{p}}-\mathrm{T}$ curve is possibly explained by the idea of the short range order induced by low temperature heat treatment.

In this investigation, the magnetic property was examined using the same specimen, that was used for measurement of specific heat. so that these experimental results might be compared one with another. The change of magnetic property induced by low temperature heat treatment was explained by introducing the idea of such an inhomogeneous internal structure as the extent of inhomogeneities is comparable with the thickness of the domain boundary and we have explained the correlativity of the magnetic property to the abnormality of the $\mathrm{C}_{\mathrm{p}}-\mathrm{T}$ curves.

In conclusion, I wish to express my heartly thanks to our director, Dr. Tamotsu Nishina for his kindly guidance and also to the many others who gave me much advice during this investigation. 